Article

\title{
Missing Hero: Co-Producing Change in Social Housing Programmes
}

\author{
Marcus Knutagård *, Cecilia Heule and Arne Kristiansen \\ School of Social Work, Lund University, Sweden; E-Mails: marcus.knutagard@soch.lu.se (M.K.), \\ cecilia.heule@soch.lu.se (C.H.), arne.kristiansen@soch.lu.se (A.K.) \\ * Corresponding author
}

Submitted: 29 March 2021 | Accepted: 25 June 2021 | Published: 26 August 2021

\begin{abstract}
The aim of this article is to develop theory and generate knowledge about the challenges and possibilities of co-producing change in a social housing programme. The purpose of the project was to implement the Housing First philosophy in the social housing programme in the city of Helsingborg, Sweden. The aim was also to create opportunities for service user involvement. Several innovative measures were implemented in order for these changes to occur from autumn 2016 to summer 2017. The social services commissioned a university course on which social workers and their clients studied together on equal terms to create project plans for the further development of their own workplace. A "Future" workshop was held by the researchers with representatives from all the different housing options (the shelter, transitional housing, category housing, Housing First apartments), both clients and social workers. Repeated dialogue meetings were conducted at the different housing options to discuss how service user involvement could be developed and to discover new ways of participation. This article is based on a strengths-based perspective using the theoretical discussions on social traps, as well as the concepts of enabling and entrapping niches. We show the importance of social workers identifying and supporting missing heroes-service users who want to participate and be involved in co-producing change. We also show that if an organisation is not prepared for the initiated changes, there is a risk of disappointment due to awakened expectations that are not fulfilled. Building trust is also an important component to emerge from the material, but we also found that change processes can be initiated that continue and have impact beyond the initial project's goals.
\end{abstract}

\section{Keywords}

co-production; enabling niches; gap mending; social housing; social traps; trust

\section{Issue}

This article is part of the issue "Home- and Community-Based Work at the Margins of Welfare: Balancing between Disciplinary, Participatory and Caring Approaches" edited by Kirsi Juhila (Tampere University, Finland), Cecilia Hansen Löfstrand (University of Gothenburg, Sweden) and Johanna Ranta (Tampere University, Finland).

(C) 2021 by the authors; licensee Cogitatio (Lisbon, Portugal). This article is licensed under a Creative Commons Attribution 4.0 International License (CC BY).

\section{Introduction}

Homelessness is a growing social problem in most European countries. The number of people experiencing homelessness is much higher in Sweden than the other Nordic countries (Benjaminsen et al., 2020; Knutagård et al., 2020). One reason for this is that the construction of new housing relative to the population growth has been lower in Sweden compared to its neighbouring countries. Consequently, the vast majority of the 290 Swedish municipalities have a shortage of rental apartments with rents that people can afford. Research highlights poverty as a significant cause of homelessness (Bramley \& Fitzpatrick, 2018; Knutagård, 2019). Without a steady income, it is extremely difficult to enter the ordinary housing market or buy your own apartment or house. There is also a growing number of people experiencing homelessness from a migrant background (Hermans et al., 2020). In two of the major cities in Sweden, local municipal guidelines have been introduced that make a distinction between what is called 'structurally homeless' and 'socially homeless' (Hermans et al., 2020; Sahlin, 2020). Being categorised as structurally homeless excludes an individual or family from 
receiving help from the social services and only emergency housing will be provided on a day-to-day basis for individual applicants, and on a weekly basis for families. Even if the causes of homelessness are seen as structural, i.e., lack of housing and not having the financial means to afford housing on the ordinary housing market, the responsibility for solving the problem is placed on the individual (Sahlin, 2020).

In the past decade there has been a shift towards a more housing-led approach (the provision of ordinary long-term housing rather than emergency housing) in how to reduce homelessness (Pleace, 2018). In the Nordic context, Finland and Norway stand out in their national strategies on housing-led approaches. One key driver in this shift is the evidence of the effectiveness of the Housing First model in enabling people using Housing First sustain their housing (Padgett et al., 2016). As a model, Housing First has its origins in the "Pathways to Housing" organisation in New York at the beginning of the 1990s; the model was the brainchild of Sam Tsemberis (Tsemberis, 2015). The model was created because Tsemberis and colleagues had identified that many former patients with whom they had worked in the mental health sector ended up sleeping rough and that the services that were available became revolving-door interventions. The services that were offered did not solve homelessness, but rather sustained the problem. The spread of Housing First to Europe and the Nordic countries started in the last decade. The results are consistent with the results of research from the USA and Canada (Pleace et al., 2019). Housing First is contrasted with the continuum of the care model or the so-called housing staircase model (Sahlin, 2005). In Housing First, housing is seen as a prerequisite and as a means of recovery and community integration, while in the staircase model, housing is seen as the end goal. In the staircase model the client is expected to progress, step by step, towards independent living. People experiencing homelessness must show that they are 'housing ready,' and the rules of different temporary housing options in the staircase model are often associated with regulations and control; an individual often has to abstain from alcohol or drugs to get an apartment. The Housing First model is based on eight core principles: (1) housing as a basic human right; (2) respect, warmth and compassion for all clients; (3) a commitment to working with clients for as long as they need; (4) scatteredsite housing and independent apartments; (5) separation of housing and services; (6) consumer choice and selfdetermination; (7) a recovery orientation; and (8) harm reduction (Tsemberis, 2015, p. 18). Research has highlighted that in order to combat homelessness, an integrated housing strategy is the way forward, based on a housing-led approach. To clarify, housing-led means that ordinary housing is used to solve homelessness. If someone runs the risk of losing their home, the first type of measure would be prevention. If someone ends up homeless, rapid re-housing in ordinary apartments should be the generic solution, while Housing First is a more specific model that is also combined with flexible support to stop people from becoming homeless (Pleace, 2018).

An important principle in Housing First is selfdetermination. This idea corresponds well with another growing practice of service user involvement in social work practice, education and research (McLaughlin et al., 2021). In Helsingborg municipality a Housing First project started in 2010 (Knutagård \& Kristiansen, 2019). The project became a permanent service in 2013 and the local politicians also decided to scale-up the Housing First programme. In the following years, the social services aimed to implement the core principles of Housing First in all the housing options in the social housing programme. The local social housing programme had its roots in a 'staircase' logic. One important aspect was to increase the service user influence at the different housing options (Knutagård \& Kristiansen, 2018). In this article we will analyse how some places and initiatives created niches that were enabling for the participants, while other places led to a niche compression and, in the end, the social trap closed. We will discuss these concepts further in the following section. We use the project in Helsingborg as a case study. The project ended in 2017. The concepts of traps emerged from the empirical material, particularly how organisational barriers prevented some participants from engaging in the change processes or made it more difficult to sustain the initiatives that had been started. The concept of enabling and entrapping niches were not active parts of the project but have emerged in our ongoing work on the gap-mending concept. The gap-mending concept entails a constant reflection on what causes and mends gaps between social workers and service users in social work practice, education and research (Askheim et al., 2017). In one of our research projects, we conducted a follow-up study of students who participated in the mobilisation course. The mobilisation course is an elective course in the seventh semester of the social work programme at the School of Social Work, Lund University. It is also offered as a commissioned course. The results of this study will be presented in a forthcoming book. We have also continued to study the implementation of Housing First in Sweden. Both examples have shown that they can generate new opportunities for participants if people can meet on equal terms. The aim of this article is to generate knowledge about the challenges and possibilities of co-producing change in a social housing programme. Our ambition in this article is theory development and we use the empirical data to illustrate our theoretical argument. We have seen synergies between project ideas that were created during the course and later realised, co-producing research projects that have included former students (by students we mean course participants who were students on the social work programme, and clients/residents and participants who were social workers) of the course and their 
project ideas with developmental work at the social service department. The synergies that we have seen made us start to think more specifically about what type of spaces enable co-production. What kind of components are necessary to create spaces that are enabling?

\section{Social Traps, Missing Heroes and Social Niches}

In this section we present the theoretical framework we have developed based on our field experience. The framework combines social traps and missing heroes with the concept of social niches.

A social trap is when actors end up in an unfavourable situation that will be disadvantageous to all of them (Rothstein, 2005). The fundamental problem with social traps is that they are very difficult to remedy. A core component is the concept of trust. When people trust each other, and particularly trust in others to participate, it is possible to create a space for co-production and collaboration. In this respect, our actions are connected to what we expect other people to do. If actors do not trust other actors to engage in a certain action, it is likely that the individual will not act on their own. This will lead to a situation in which the outcome will be irrational for the collective, but the action might be rational for the individual. Rothstein $(2005$, p. 13 ) connects trust with the collective memory-it is difficult to "rationally decide to forget." This type of situation can have devastating consequences. A key concept in Rothstein's argument is anticipation. A collective memory of persecution, discrimination and violence is not easy to forget and is connected to the stories that are being told by different categories of 'the others.' Rothstein $(2005$, p. 21 ) points out that social traps can lead to "stable but inefficient equilibria." This is a situation in which the actors involved have no incentive to make any effort to change their behaviour or actions. There can be short-term benefits for some actors, but the state of inefficient equilibria will, in the long-term, be negative for everyone involved. The problem is that when people start to distrust each other, the risk of ending up in a social trap rather than a collaborative change process is present. This elucidates the relationship between trust and social traps. It takes time to establish trusting relationships, but it is easy to destroy a relationship by not being trustworthy. Both mistrust and social traps are situations that involve a lot of work, time and loyalty to rebuild, once the trust is lost and the trap has closed.

When groups are prejudiced towards each other, it is very difficult to overcome the mistrust that exists between them. However, there are certain conditions that can circumvent the prejudice in intergroup contacts:

Prejudice (unless deeply rooted in the character structure of the individual) may be reduced by equal status contact between majority and minority groups in the pursuit of common goals. The effect is greatly enhanced if this contact is sanctioned by institutional supports (i.e., by law, custom or local atmosphere), and provided it is of a sort that leads to the perception of common interest and common humanity between members of the two groups. (Allport, 1979, p. 281)

These four conditions can reduce prejudice in intergroup contact: (1) equal status; (2) common goals; (3) cooperation between groups; and (4) institutional support (Pettigrew \& Tropp, 2011, p. 61). Allport (1979, p. 9) states that "prejudgments become prejudices only if they are not reversible when exposed to new knowledge." Subsequent research has confirmed Allport's contact hypothesis and a meta-study conducted by Pettigrew and Tropp (2006) showed that of the four identified factors, the most important one was institutional support. Institutional support and long-term commitment, as we will show, are crucial for enabling co-produced projects to be sustainable.

In this article, we see the hero as a person who is keen to get involved in co-production. The missing hero could be the same person, because if the context is not right, the person will not participate (Platt, 1973). The reason for this depends on whether the person believes that other people will also get involved in the change process and also whether the environment can be seen as an enabling niche rather than a niche that is entrapping.

Taylor (1997, p. 219) defines a social niche as the "environmental habitat of a category of persons, including the resources they utilize and the other categories of persons they associate with." By using an ecological metaphor, Taylor places the focus on the relationship between human beings and the environment. For human beings, the immediate environment can be seen as the 'community' and the 'neighbourhood' (Ryke et al., 2004). In order to include a strengths perspective and how a place can be symbolic and subjectively constructed, Ryke et al. (2004) extended Taylor's original definition. They define the social niche as:

The living environment of people, including the place in which people find themselves and the places typically utilised by them, the circumstances of that place, both social and natural/physical, the resources available to them and typically used by them, the other categories of people who are typically associated with those people, the contribution or initiative of people in it and the meaning that people construct in regard to their place and purpose. (Ryke et al., 2004, p. 1935)

What we are particularly interested in here is the distinction Taylor (1997) makes between enabling and entrapping niches. The distinction between the two illustrates ideal types, but even though niches exist in a purer form, they often contain both enabling and entrapping aspects. The enabling niche can be seen as a strong environment and therefore minimises the risk of getting 
into a social trap because the people who belong to the enabling niche are ready to surrender their individuality for the good of their community (Ryke et al., 2004). Often, entrapping niches are places that the most marginalised groups in society are more or less forced to inhabit.

The entrapping niche is characterised by a space that stigmatises those who are trapped. The social category defines the members of the niche. This categorisation is particularly done by people outside of the niche. People within the niche tend to only associate with each other, which limits their social relationships. There are very limited economic resources and limited opportunities to achieve a higher status or position in an entrapping niche. It is also more difficult to have long-term goals and it is hard to acquire skills that can help a person to escape (Rapp \& Goscha, 2012; Taylor, 1997). Homelessness, for example, increases the likelihood of people ending up in an entrapping niche.

Being part of an enabling niche does not stigmatise and people in the groups are not only defined by their social category. Even though people in the niche mainly associate with other people in the niche, there are opportunities to interact with others. The economic resources are sufficient in enabling niches. The niche offers opportunities to work towards long-term goals and there are also opportunities to get higher positions and learn new skills that enable a person to progress to other niches (Rapp \& Goscha, 2012; Taylor, 1997). Gap-mending strategies are an example of how the interaction between niches can be mended to increase the possibilities for people to escape previous entrapping situations and positions (Heule et al., 2017). In order to mend the gaps, participants need to reflect on the factors that caused the gaps. This process takes time, as trust might require participants to look beyond their prejudiced views of each other.

This article is based on a strengths-based perspective. Instead of focusing on deficiencies or shortcomings, people's inherent strengths are at the fore. In a strengthsbased approach, well-being and the human potential is the fundamental focus. In a problem-orientated approach, "the client's situation must be made to fit predetermined categories and those categories are not the ones that the client would devise as an adequate description of his or her situation" (Rapp \& Goscha, 2012, p. 7). The client's problems are seen as being caused by themselves, which also makes them responsible for their own situation. If we take homelessness as an example, this is often the case. Blaming the victim can result in an inverted model of cause and effect (Whang \& Min, 1999) comprising four stages:

All of this happens so smoothly that it seems downright rational. First, identify a social problem. Second, study those affected by the problem and discover in what ways they are different from the rest of us as a consequence of deprivation and injustice. Third, define the differences as the cause of the social prob- lem itself. Finally, of course, assign a government bureaucrat to invent a humanitarian action program to correct the differences. (Ryan, 1976, pp. 8-9)

One challenge is that those action programmes or interventions that are intended to cater for marginalised groups tend to be niches that are entrapping rather than enabling.

\section{Participatory Action Research}

The design of our research project is based on participatory action research (Bradbury, 2015). There are four main reasons why we have considered this approach to be relevant. The first concerns ethics. There are ethical aspects about giving all interested parties the opportunity to participate, ensure that their voices are heard and their perspective is given the same space as the voices of researchers and practitioners (Askheim et al., 2019; Beresford, 2005). Another important area is about quality and improvements. Many people believe that research is improved if service users participate because the questions they ask are different from the questions asked by researchers and practitioners. Service users can also facilitate access and involvement of other service users in research projects (Askheim et al., 2019; Brydon-Miller et al., 2004; McLaughlin, 2009). A third area addresses the importance of personality development. Participating in action research can result in developing the participants' personality (Askheim et al., 2019; McLaughlin, 2009). The fourth area is human rights. This is similar to the ethical perspective in action research. The focus is on giving marginalised and discriminated groups the opportunity to give their perspectives on social problems (Askheim et al., 2019; Beresford, 2005; Brydon-Miller et al., 2004).

The empirical material of this study comprises field notes from 26 dialogue meetings at the different housing options in the social housing programme. Field notes from five steering group (project group) meetings are also included, as well as documentation from one "Future" workshop. One taped interview with a social worker and an expert by experience is also used. In this interview the focus was on the experience of participating in a participatory action research project. As researchers, we have participated in different ways. We have all taught on the commissioned course used by the social services as one of its initiatives to create a space for co-producing change. We held the "Future" workshop and participated in the dialogue meetings. During the entire project there has been a project group that included representatives from the social services, social workers from different housing alternatives, people with experience of homelessness or other social problems, representatives from the Research and Development unit in the city, as well as researchers.

Our ambition was to try to maintain a continuous dialogue with the other participants (social workers, experts 
by experience, residents at the different housing options) in the project in order to strengthen the collaboration and interactions with them. These are important prerequisites for participatory action research to work (Grant et al., 2008; Kristiansen, 2016). For example, this meant that at our project meetings we reflected on our roles as well as the other participants' roles in the project and how we could develop and improve the dialogue meetings. In relation to the meetings, we reflected on the four conditions described by Allport (1979) that are essential in intergroup contact (equal status, common goals, cooperation between the groups, and institutional support). We also invited and engaged the service users in the research process. They designed a questionnaire on their own and interviewed people with lived experience of homelessness. It is important, however, to recognise that there are also some risks involved in participatory action research. There are ethical problems regarding, for example, confidentiality. It can be difficult to guarantee confidentiality and it is therefore important to ensure that everyone is informed about what is expected of them and what they themselves can expect from the research project (Gelling \& Munn-Giddings, 2011, p. 105). Askheim and Raak Høiseth (2019) state that service users should participate on the same terms as researchers and service users must therefore be informed and educated about confidentiality and other research ethics, etc. There could also be conflicts related to the goals and intentions of the project. It is important to ensure that participants are involved in the initiative, as well as the influence and design of the study (Gelling \& Munn-Giddings, 2011, p. 105). If the participants are not properly invited to participate in the project, their involvement might become a form of tokenism (McLaughlin, 2009).

\section{Co-Producing Change}

The municipality, more specifically, the social services department, had successfully implemented a Housing First programme in the city. The results showed a high housing retention rate: $85 \%$ of tenants were still housed after the Housing First project ended in 2013 (Table 1). The tenants reported positive life changes such as better contacts with family and friends, better health, and a bet- ter financial situation. The tenants also stated that their trust towards social services had increased (Knutagård \& Kristiansen, 2018; Kristiansen, 2013). The positive results from the Housing First programme led to the desire to try and change the whole social housing programme by introducing the core principles of the Housing First model. The key objective was to increase the involvement of service users in the different housing options in the local social housing programme used by the social services in its homelessness work: emergency housing; low threshold housing; transitional housing; training flats; and social housing apartments (Table 2). Even though the Housing First apartments were part of the same organisation, the other housing options in the social housing programme were based on a staircase logic.

Three key activities were used to enable the involvement of the residents in the different housing options and to investigate the possibility of the different measures that could be taken. The social services commissioned a course that is held at Lund University (Heule et al., 2017). During the course, social work students study together with people with lived experience of different problems such as homelessness, mental health problems or substance abuse, etc. During the course, one of the tasks is to co-create project plans that aim to tackle a current social problem. At this stage, the social services recruited 'students' who were both residents and staff at the different housing options. This enabled them to take the course together, and when designing the project plans, they could target their ideas towards the question of how to increase service user involvement in the social housing programme in the city. During the course, a "Future" workshop was held to kickstart the work on the projects (Jungk \& Mullert, 1987). The "Future" workshop is a good way of getting everyone involved and participating, as well as ensuring that all voices are heard. Because of the action-orientated outcomes of the "Future" workshop, and the fact that the course could only be held once per semester, with a limited number of students, the social services asked the researchers to organise an additional "Future" workshop. This enabled more residents and staff to participate. The third activity to be initiated was dialogue meetings. These meetings were held at the different housing

Table 1. Housing First in Helsingborg 2010-2017 (number of tenants, evictions and housing retention rate).

\begin{tabular}{lccc}
\hline & Tenants & Evictions & Retention rate \\
\hline 2010 & 2 & - & 100 \\
2011 & 9 & $0(0)$ & 100 \\
2012 & 16 & $1(1)$ & 93.75 \\
2013 & 20 & $2(3)$ & 85.00 \\
2014 & 34 & $0(3)$ & 91.18 \\
2015 & 44 & $3(6)$ & 86.37 \\
2016 & 49 & $0(6)$ & 87.76 \\
2017 & 57 & $3(9)$ & 84.22 \\
\hline
\end{tabular}


Table 2. The Social Housing Programme in Helsingborg 2017.

Social housing/rental guarantee apartments

Type of accommodation: 2 nd hand contract. The rental guarantees are 1st hand contracts with additional contracts.

Target group: Addiction and mental health problems.

Number of places: Around 165 apartments, of which around 30 are rental guarantees.

Description: For people who are self-sufficient and follow the rules of the Rent Act.

Staff: $7+1$ coordinator.

The staff's mission: Support, motivation, and supervision. The staff's mission: Support, motivation and ADL (activities of daily living).

\section{Fenix-Emergency housing}

Type of accommodation: Emergency housing and long-term housing for people who temporarily do not have the ability to manage their own housing.

Target group: Addiction and mental health problems.

Number of places: 31 permanent places +6 places that can be used without a referral from the social services.

Description: For people who are active addicts.

Staff: $12+1$ coordinator.

The staff's mission: Support and motivation.

Carnot-Training apartments

Type of accommodation: Training apartments.

Target group: People with drug addiction with greater support needs.

Number of places: 18 smaller apartments with shared kitchen (6 apartments/kitchen), 10 individual apartments and two 6-room apartments. A total of 34 places.

Description: The residents must be motivated to move on to their own apartment or a social housing apartment.

Staff: $8+1$ coordinator.

\section{G8-Training apartments}

Type of accommodation: Training apartments.

Target group: Addiction, people who are regarded as being capable of managing their own housing with support.

Number of places: 47 in apartments. 3 apartments are used as 'temporary places' when people relapse. These apartments are shared with Pluto.

Description: The residents must be motivated to move on to their own apartment or a social housing apartment.

Staff: 4.

The staff's mission: Support, motivation, and ADL.

Kronan-Congregate supported housing Pluto-Training apartments

Type of accommodation: Congregate supported housing for people with more severe comorbidity (two or more conditions that a person experiences, e.g., substance abuse and mental health problems).

Target group: Addiction and mental health problems.

Number of places: 17 independent apartments +1 apartment with 3 places.

Description: People with a great need for support.

Staff: 8.

The staff's mission: Support, motivation, and ADL.

Type of accommodation: Training apartments. Requirements of abstinence.

Target group: Addiction and/or mental disability.

Number of places: 56 . Three apartments are used as 'temporary places' when people relapse. These apartments are shared with G8.

Description: People who remain abstinent and are motivated to move on to their own apartment or a social housing apartment.

Staff: 4.

The staff's mission: Motivation and ADL training.

\section{Housing First}

Type of accommodation: Own apartment, 1st-hand contract with additional agreement for the first two years.

Target group: People with substance abuse and mental health problems.

Number of places: Unlimited based on access to apartments. Currently 32 apartments. The programme has been allocated a total of 57 apartments, of which around 20 have been transferred to the residents with their own contracts.

Description: For long-term homeless people who are motivated to change.

Staff: 3.75 .

The staff's mission: To give the individual active support and motivation in their pursuit of change, which could involve reduced substance abuse, employment, as well as supporting the individual in following the rules of the Rent Act. 
options on several occasions. The ambition was to listen to the views of participants, residents and tenants on practice local service user involvement and what kind of changes they wanted to see and in what way they could be part of this change. One of the participants stated: "It took a while for them [the service users] to understand that it was for real, that something was happening... it was not just talk and more talk." The course design considered the principles of contact research insofar as the participants were all students (equal status). They developed projects together (cooperation towards common goals) and this was supported by leadership in the city of Helsingborg (which could be seen as institutional support).

Inherent to the Housing First model is enabling tenants to be involved and decide what they need in order to stay housed and to recover. The tenants in the Housing First programme also had a place where they could meet, to meet up with other residents, support workers, and just sit down and have a coffee and talk for a while. They had their own apartments to which they could return. The housing options in the social housing programme differ greatly regarding the individual's own space and integrity. Many of the people who lived in other types of housing situations had to share kitchens and bathrooms, and their 'own' rooms might be visited by other residents or staff. The rules that regulate the place might therefore threaten the individual's integrity. In most cases, regulations regarding the work environment and staff safety come first. Housing options in the social housing programme (e.g., emergency shelters, transitional housing, training flats) run the risk of "violating a person's space, time, energy, mobility, bonding, and identity" (Rapp \& Goscha, 2012, p. 12).

For people experiencing homelessness, this type of problem is always significant and the fact that such problems exist also contributes to their lack of trust in social workers and various authorities. We have learned that if we want to engage people and get them involved in participatory action research projects, we need to show them that we take their everyday problems seriously. This can build trust and make it worthwhile for them to participate in the project. The different initiatives that were used in the project had the ambition to create a space in which everyone could be involved on equal terms. Rothstein raises an important point:

The thought is that we may be prepared to seriously listen to and accept opinions and arguments from those whose interests or ideas are different from our own, but only provided that we can trust that the other side is equally ready to do so. (Rothstein, 2005, p. 51)

During the project, enabling niches were created for the participants. We will show two examples. In the first example, the enabling niche could not be sustained. The project idea that was created was supposed to be imple- mented in one of the housing options, but the institutional support was not sufficient, so the social trap closed. In the other example, the combination of enabling niches created opportunities for the participants to get a job, study, or had other positive outcomes. Having a Housing First apartment was in itself an enabling niche.

\section{The Trap Closes}

During the project period, some of the niches that had enabled the co-production of change started to close. During the so-called mobilisation course, several residents became involved in project ideas that they believed were plausible and possible to implement, and which were supported by their fellow residents and staff. There was one person in particular, Murray, who can be seen as a missing hero. He and several others put in a lot of effort to increase the residents' influence on the daily life at the housing unit where he livedcongregate transitional housing. This place comprised separate rooms in which the residents lived, but with a shared kitchen and other facilities. There were apartments close by that were also connected to this house. This was one of the difficulties in getting all the residents involved in the process, because those residents living in apartments had their own space and were not as dependent on the shared spaces. For many of the residents living there, having something meaningful to do was high on their priority list. They started table-tennis tournaments between the housing options in the social housing programme. Another challenge was that it took a lot of time from the point when an issue or suggestion was raised to receiving a green light from the management. The entire project had institutional support from the top end of the management, but the understanding of what the project was really about was not sufficient in the middle management. This resulted in gaps between those who participated on the ground level, and the different management levels between the residents and the director of social services. The support was from a management group that was quite far removed from the daily decision making of the housing option. This had serious consequences for Murray and the project idea he was trying to implement, since he was not given the necessary resources to take it further. It was not a question of a huge amount of money, just a small sum that would give the residents cash to travel by bus between the different housing alternatives, or to buy paint to re-paint the units. Even the staff who had participated in the joint course encountered difficulties. When enabling niches face a lack of resources, it leads to what is called a niche compression. It was a very ambitious project in many ways and it really tried to make provision for the participant being part of and co-creating the actions needed to strengthen the possibilities of service user involvement. The project funding was only for one year (the second half of 2016 to the first half of 2017, so-called seed money), with the main focus on investigating how service 
user involvement could be implemented. This created some confusion, since once the project had started, the residents and staff were more interested in creating real change, rather than figuring out what could be changed.

\section{A Niche That Enables}

Location is an important factor in the discussion about enabling niches. Some physical locations are less likely to be enabling than others. In our research there is another key component that is key: relationships. Relationships are key to creating and sustaining enabling niches. As we have previously seen, the challenges of sustaining the initiated change process were a lot harder at the more congregate housing options. One of the Housing First tenants, Bertha, describes her experience of taking the course:

Emma [the support worker] forced me to attend the mobilisation course. She has always pepped me and supported me....Then you stood there, you two, you and Marcus, friendly professors and listened to me, you probably don't understand how much it meant to me....The actual work on the mobilisation course, I don't know if I can put it into words, but you got a completely different kind of self-esteem... suddenly you meant something... my group was important... yes, I actually felt like a real human being... and not just an old drug addict. It was at the mobilisation course that I got in touch with you....It was a completely different world for me.

Bertha's statement shows the importance of the mobilisation course as a niche that enabled and empowered Bertha to believe in the power of the group and that gave her new confidence about who she was. Being acknowledged and approved by fellow students and teachers had a gap-mending effect that also affected her selfconfidence and trust after the course. Bertha was subsequently employed as a support worker in one of the housing options and had many representative assignments within the network of the commissioned course. The value system and the institutional norms between the course and the Housing First project were more in line than other housing options in their vision of enabling and listening to marginalised groups. However, as enabling niches, both the commissioned course and the Housing First project depended on the surrounding institutions, which also limited the effects for the participants.

Even though it was more difficult to transform the housing options in the social housing programme, a few significant transitions can be noted. There was a stronger focus on housing retention, i.e., that the residents would not be evicted if they relapsed. One critical aspect of the project was that the staff who worked with Housing First found it hard to be involved in implementing the Housing First principles in the other parts of the social housing programme. According to a social worker:
There was never anything, there was talk, but many of us were ready to board this ship. I compared it to a large ship... that we were ready to board, but it became a ship with a lone sailor and I was not allowed to join and I had loads of ideas about how to work. Finally, we would get to do something useful and there were many more than me who were excited about it, but it became only a word, housing retention, and it was interpreted differently, depending on the housing option.

Even though the ambition was to implement the core principles of Housing First in the social housing programme, the experience and knowledge of the Housing First support workers were not used. One of the support workers told us that "our boss wanted to call Stockholm and learn about how they worked with Housing First, when everyone else [within the organisation and from other municipalities] called us and asked us [about how to work with Housing First]." This led to a niche shift, which meant that some of the Housing First staff decided to leave their jobs and start their own businesses. In this way, they created a new platform where they could make the most of their potential and experience.

\section{Conclusion}

When we look at the outcome of the different measures, they all created enabling niches. The problem was that it was much more difficult to sustain the enabling niche in the more congregate housing options in the social housing programme than in the Housing First programme. These findings support a more housing-led approach to ending homelessness since having your own apartment is an enabling niche in itself. Even though housing is essential, having a job or having something to do and feeling a sense community is also important. In this context, creating spaces (both physical and virtual) that are enabling can enhance the options. The results suggest that the potential of enabling niches lies in between cross-sectoral collaborations rather than within specific services. It is not impossible to transform more congregate housing options into enabling niches, but it is a lot harder due to competing institutional logics. The results show the importance of social workers identifying and supporting missing heroes-service users and staff who want to participate and be involved in co-producing change. The results also show that if an organisation is not prepared for the initiated changes, there is a risk of disappointment due to awakened expectations that are not fulfilled. Building trust is also an important component to emerge from the material, and trust will decrease if what is said and what is done are two different things. The results have also shown that change processes can be initiated that continue to have an impact beyond the initial project's goals.

The results of this study correspond with the conditions that Allport highlight as necessary in intergroup 
contact. They also correspond with the concept of enabling niches. Gordon Allport's findings show that under certain conditions, contacts between rival groups could reduce prejudice and discrimination. As previously mentioned, the conditions that were seen as important were: equal status, common goals, intergroup cooperation and the support of authorities, laws or customs. None of these conditions are easy to adopt, particularly not in institutions or organisations that are characterised by a clear hierarchy between service users and employees. Some of the housing options that participated in our research project could be compared to Goffman's total institutions. They upheld many procedures that were disciplinary towards service users and which threatened their integrity (Goffman, 1991). Even if employees and residents from these organisations were able to develop mutual trust as students on equal grounds within the framework of the mobilisation course, this framework had a very limited bearing on the housing organisation, which was characterised by a different institutional norm. Both employees and tenants from these organisations testified that they had been disillusioned by the difficulties they faced in their joint efforts to change their organisation in order to better respond to the needs of those people who lived there. Allport specified that unless the contacts were characterised by informal personal interaction and cross-group friendships, the contacts would risk becoming superficial and would cause people to resort to stereotypes. In environments that resemble total institutions, the gaps tend to be upheld and cross-group friendships will be disciplined and punished. However, our study also showed that enabling niches can enhance the effect of empowerment for marginalised groups that use one niche as a steppingstone to another niche. Some students were empowered by the mobilisation course and were subsequently employed by other organisations, such as the Housing First programme, which acknowledged their growth and potential.

This article has analysed a case that shows that both staff and service users can become motivated and build mutual trust in enabling niches, characterised by more equal status and which enable cooperation and the development of common goals. However, if these values are not supported by the larger institutional setting, they have limited sustainability and can lead to renewed prejudice and disappointment. It also shows that institutional change takes both time and long-term commitment on the part of management at all levels of the involved organisations.

\section{Acknowledgments}

We would like to thank the City of Helsingborg for funding the project through Plattformen's research grants, during the period of 2014-2016. We would also like to thank all the participants in the research project for their time and commitment.

\section{Conflict of Interests}

The authors declare no conflict of interests.

\section{References}

Allport, G. W. (1979). The nature of prejudice. Perseus Books.

Askheim, O. P., Beresford, P., \& Heule, C. (2017). Mend the gap-Strategies for user involvement in social work education. Social Work Education, 36(2), 128-140.

Askheim, O. P., Lid, I. M., \& Østensjø, S. (2019). Samproduksjon i forskning-Hva er det, og hva innebærer det? [Co-production in research-What is it, and what does it mean?] In O. P. Askheim, I. M. Lid, \& S. Østensjø (Eds.), Samproduksjon i forskning. Forskning med nya aktører [Co-production in research. Research with new actors] (pp. 13-35). Universitetsforlaget.

Askheim, O. P., \& Raak Høiseth, J. (2019). Medforskerrollen-I spenningsfeltet mellom anerkjennelse, kooptering og "Tokenisme" [The role of the coresearcher-In the tension field between recognition, co-optation and "Tokenism"]. In O. P. Askheim, I. M. Lid, \& S. Østensjø (Eds.), Samproduksjon i forskning. Forskning med nye aktører [Co-production in research. Research with new actors] (pp. 214-230). Universitetsforlaget.

Benjaminsen, L., Dhalmann, H., Dyb, E., Knutagård, M., \& Lindén, J. (2020). Measurement of homelessness in the Nordic countries. European Journal of Homelessness, 14(3), 159-180. https://www. feantsaresearch.org/public/user/Observatory/2021/ EJH_14-3_A7_v02.pdf

Beresford, P. (2005). Developing the theoretical basis for service user/survivor-led research and equal involvement in research. Epidemiologia e Psichiatria Sociale, 14(1), 4-9.

Bradbury, H. (Ed.). (2015). The SAGE handbook of action research (3rd ed.). SAGE.

Bramley, G., \& Fitzpatrick, S. (2018). Homelessness in the UK: Who is most at risk? Housing Studies, 33(1), 96-116. https://doi.org/10.1080/02673037. 2017.1344957

Brydon-Miller, M., Maguire, P., \& Mclntyre, A. (Eds.). (2004). Traveling companions: Feminism, teaching, and action research. Praeger.

Gelling, L., \& Munn-Giddings, C. (2011). Ethical review of action research: The challenges for researchers and research ethics committees. Research Ethics, 7(3), 100-106. https://doi.org/10.1177/1747016111 00700305

Goffman, E. (1991). Asylums: Essays on the social situation of mental patients and other inmates. Penguin.

Grant, J., Nelson, G., \& Mitchell, T. (2008). Negotiating the challenges of participatory action research: Relationships, power, participation, change and credibil- 
ity. In P. Reason \& H. Bradbury (Eds.), The SAGE handbook of action research. Participative inquiry and practice (pp. 589-601). SAGE.

Hermans, K., Dyb, E., Knutagård, M., Novak-Zezula, S., \& Trummer, U. (2020). Migration and homelessness: Measuring the intersections. European Journal of Homelessness, 14(3), 13-34. https://www. feantsaresearch.org/public/user/Observatory/2020/ EJH/EJH_14-3_A1_v02.pdf

Heule, C., Knutagård, M., \& Kristiansen, A. (2017). Mending the gaps in social work education and research: Two examples from a Swedish context. European Journal of Social Work, 20(3), 396-408. https://doi. org/10.1080/13691457.2017.1283589

Jungk, R., \& Mullert, N. (1987). "Future" workshops: How to create desirable futures. Institute for Social Inventions.

Knutagård, M., \& Kristiansen, A. (2018). Nytt vin i gamla läglar: Skala upp Bostad först, boendeinflytande och om att identifiera och stötta "the missing hero" [New wine into old wineskins: Scaling up Housing First, service user involvement and to identify "the missing hero"]. School of Social Work, Lund University.

Knutagård, M., \& Kristiansen, A. (2019). Scaling up Housing First pilots-Drivers and barriers. Nordic Journal of Social Research, 10(1), 1-23. https://doi.org/ $10.7577 /$ njsr.2175

Knutagård, M. (2019). Ekonomiskt bistånd och hemlöshet [Income support and homelessness]. In T. Hjort (Ed.), Det yttersta skyddsnätet: Om arbete med socialbidrag [The outermore safety net: About work with income support] (pp. 223-245). Studentlitteratur.

Knutagård, M., Kristiansen, A., Larsson, K., \& Sahlin, I. (2020). Homelessness. Research Brief, 14, 1-8. https://forte.se/app/uploads/sites/2/2020/09/ forskning-i-korthet-en-hemloshet.pdf

Kristiansen, A. (2013). Utvärdering av Bostad förstprojektet $i$ Helsingborg. Slutrapport [Evaluation of the Housing First project in Helsingborg. Final report]. Socialförvaltningen, Helsingborgs stad.

Kristiansen, A. (2016). Forskning och social mobilisering [Research and social mobilization]. In V. Denvall, C. Heule, \& A. Kristiansen (Eds.), Social mobilisering. En utmaning för socialt arbete [Social mobilization. A challenge for social work] (pp. 65-78). Gleerups.

McLaughlin, H. (2009). Service user research in health and social care. SAGE.
McLaughlin, H., Beresford, P., Cameron, C., Casey, H., \& Duffy, J. (Eds.). (2021). The Routledge handbook of service user involvement in human services research and education. Routledge.

Padgett, D., Henwood, B. F., \& Tsemberis, S. J. (2016). Housing First: Ending homelessness, transforming systems, and changing lives. Oxford University Press.

Pettigrew, T., \& Tropp, L. (2006). A meta-analytical test of intergroup contact theory. Journal of Personality and Social Psychology, 90(5), 751-783.

Pettigrew, T. F., \& Tropp, L. R. (2011). When groups meet: The dynamics of intergroup contact. Psychology Press.

Platt, J. (1973). Social traps. American Psychologist, 28(8), 641-651.

Pleace, N. (2018). Using Housing First in integrated homelessness strategies. A review of the evidence. Centre for Housing Policy, University of York.

Pleace, N., Baptista, I., \& Knutagård, M. (2019). Housing First in Europe: An overview of implementation, strategy and fidelity. Housing First Europe Hub.

Rapp, C. A., \& Goscha, R. J. (2012). The strengths model: A recovery-oriented approach to mental health services (3rd ed.). Oxford University Press.

Rothstein, B. (2005). Social traps and the problem of trust. Cambridge University Press.

Ryan, W. (1976). Blaming the victim. Vintage Books.

Ryke, E., Strydom, H., \& Botha, K. (2004). The social niche: Conceptualising the human environment. International Journal of the Humanities, 2(3), 1935-1944.

Sahlin, I. (2005). The staircase of transition. Survival through failure. Innovation, 18(2), 115-136.

Sahlin, I. (2020). Moving targets: On reducing public responsibilities through re-categorising homeless people and refugees. European Journal of Homelessness, 14(1), 27-54.

Taylor, J. B. (1997). Niches and practice: Extending the ecological perspective. In D. Saleebey (Ed.), The strengths perspective in social work practice (pp. 217-227). Longman.

Tsemberis, S. J. (2015). Housing First: The pathways model to end homelessness for people with mental health and substance use disorders. Hazelden.

Whang, I., \& Min, E. (1999). Blaming the homeless: The populist aspect of network TV news. In E. Min (Ed.), Reading the homeless: The media's image of homeless culture (pp. 121-133). Prager.

\section{About the Authors}

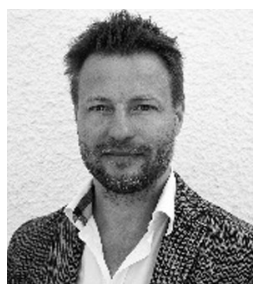

Marcus Knutagård is an Associate Professor at the School of Social Work, Lund University. His research interests include housing policy, homelessness and the importance of place for how social work is organised-its moral geography. Two of his ongoing research projects are "Scanian Homes: Reception, Settlement or Rejection-Homelessness Policies and Strategies for Refugee Settlement" and "Take Away-Disinvestment of Established Methods When Implementing New Psychosocial Interventions for Homeless People and People with Mental Health Problems." 


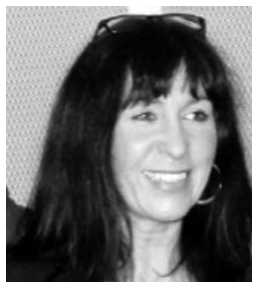

Cecilia Heule is a university Teacher and a PhD candidate at the School of Social Work, Lund University. She is one of the originators of the Mobilization Course. In 2011-2013 she coordinated a Leonardofunded international partnership that was the start of the network PowerUs. Her upcoming thesis is a qualitative study based on the experimental practice that she and her colleagues have designed in order to understand gap-mending principles.

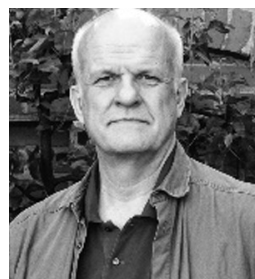

Arne Kristiansen is an Associate Professor at the School of Social Work, Lund University. His research includes substance abuse, homelessness and service user involvement. Currently he is involved in a research project related to municipal homelessness policies and refugee reception strategies in south of Sweden and a research project on service user involvement in social work. He is a member of the international network PowerUs, The Nordic Network for Homelessness Research and the Social Science Network of Alcohol and Drugs (Sonad). 